\title{
Adoption Lag Minimization for Increasing Rice Yield
}

\author{
B Karmakar1 ${ }^{*}$, M M Rahman², M A R Sarkar³, M A A Mamun, M C Rahman³, B Nessa ${ }^{5}$, M U Salam6 and M S Kabir 7
}

\begin{abstract}
Sustainable adoption of promising technology leads to increase yield and productivity of rice significantly. Yield gap reduction through minimization of adoption cycle of rice technologies is essential to increase food security of Bangladesh. Adoption of promising rice variety required $16 \pm 3$ years to reach its adoption peak at farm level following the existing dissemination protocol. The specific objective is to find out the ways and means to curtail adoption lag of variety, management practices and rice based technologies for sustainable food security of Bangladesh. The study is accomplished accordingly by reviewing previous works completed on technology adoption; calculation and estimation of future seed demand and supply. Our findings reveal that the average yield gap between actual farm yield and potential farm yield is $20.7 \%$. Seed retention and motivated farmers estimated from the frontline demonstrations of BRRI were 18 and $20 \%$, respectively. Sufficient amounts (128 $\mathrm{kg} /$ variety) of breeder seed need to be produced by the concerned research organizations concurrently the variety release process. The seed will be used to execute action plan by setting up 64 adaptive trials (AT) in 64 districts to select location specific suitable variety(s) for rapid dissemination. In the $2^{\text {nd }}$ and $3^{\text {rd }}$ years, $256 \mathrm{~kg}$ quality seeds per variety will be required to conduct $128 \mathrm{AT} / \mathrm{SPDP}$ in 64 districts. The seed of farmers' chosen variety(s) will be collected, stored, and marketed by the local seed producer or farmers group; and they will provide this information to the extension organization and BRRI. At least 10 to $20 \%$ seed selling information will be checked by the concerned scientist of BRRI every year and total seed selling data will be calibrated based on the checked data. Similarly, the next two years' trial data will be collected from conducted trials and associated seed producer/dealer/farmers' club/groups. Then, the concerned research institute will be able to provide a projection of diffusion rate and demand of newly released variety(s) compiling three years data. Based on the authentic reports, the concerned organizations will conduct block, frontline and follow-up demonstrations in collaboration with all the stakeholders. Action plan of research and extension; large scale frontline demonstration of the selected variety(s) with more stakeholders followed by field day, training, and workshop would be the key drivers for effective and sustainable dissemination of technology lead to reduce adoption lag effectively. Combined initiatives and integrated approaches need to be taken nationally to execute the adoption lag minimization plans and model for rapid dissemination of promising technology to doubling the rice productivity. Therefore, popularization and adoption of new technology would be possible within five to seven years instead of $16 \pm 3$ years.
\end{abstract}

Key words: Rice variety, yield gap minimization, demonstration, dissemination, varietal and seed replacement rate.

\section{INTRODUCTION}

Adoption means the integration of new technology into existing ones; it normally progresses over a period of time through trial and error and, some degree of adaptation (Loevinsohn et al., 2013). Adoption lag is the time (years) needs for a new technology to reach its peak of adoption from its release (Kabir et al., 2020). Adoption lag varies from technology to technology depending on its suitability, profitability, environmental and social acceptability. It has been reported that adoption of new rice variety is often required $16 \pm 3$ years to reach its peak from its release (Kabir et al., 2015). Adoption lag is one of the major factors responsible for the yield gap and plays a vital role in the sustainable food security of a country including Bangladesh. The technology adoption rate remains low in

1Principal Scientific Officer and 2 Senior scientific Officer, Adaptive Research Division; 3 Senior Scientific Officer, Agricultural Economics Division, 4 Scientific Officer, Agricultural Statistics Division, ${ }^{3 S e n i o r}$ Scientific Officer, ${ }^{5}$ Plant Pathology Division; Bangladesh Rice Research Institute (BRRI), Gazipur, Bangladesh; ${ }^{6}$ Freelance Researcher, Bangladesh, ${ }^{7}$ Director General, BRRI, Gazipur, Bangladesh

*Corresponding author's E-mail: biswajitbrri@gmail.com 
developing countries (Mwangi and Kauriuki, 2015; Mottaleb et al., 2015). For example, the popular mega varieties BR11, BRRI dhan28, BRRI dhan29 took about 16 years to attain their highest peak of adoption. These varieties now a day become highly susceptible to pests as those have been in the field for many years.

Varietal replacement is one of the vital concerns and essential to increase rice yield and productivity. Strengthening seed multiplication and distribution system is a must to increase the adoption and dissemination of improved varieties (Singh and Singh, 2016). Improved varietal replacement rates (VRR) and increased seed replacement rates (SRR) have significant effects to minimize adoption lag and also enhance crop productivity. The optimistic role of both VRR and SRR increased the productivity of rice by $27.9 \%$ from $2007-08$ to 2014-15 that contributed to improving food security in Jharkhand state of India (Singh and Singh, 2016).

Farmers' perspective is very important for sustainable adoption of technology. Varietal performances have significantly influenced the farmers' perception and decision to adopt it. Adesina and Zinnah (1993) rightly mentioned that persuasive decision of adoption or rejection of technologies depends on farmers' perceptions of the appropriateness or inappropriateness of the technologies. In order to improve technical efficiency at farmers' levels, they ought to encourage adopting more effective rice technologies. Abdulai et al. (2018) observed that the technical efficiency of adopter farmers increased by $10 \%$ compared to non-adopters of rice technologies that have a significant effect on technology adoption. Bangladesh government is very much enthusiastic to reduce adoption lag as well as yield gap. The concerned government organizations (GOs) and also some nongovernment organizations (NGOs) are working to minimize adoption lag for increasing rice yield. However, those efforts are still far behind to minimize the gap. Lack of smart, competent, and sustainable technology is also an imperative factor to reduce adoption lag. Research organizations are developing a lot of technologies. However, they have not enough information that the technologies are suitable and sustainable for the end-user, or not. Farmers have independent preferences for technology characteristics (Ashby and Sperling, 1992) and these could play a major role in technology adoption. In-substantial dissemination system, lack of smart technology, lack of availability of technology at the root level, land tenure, land size, good communication; socioeconomic factors are responsible for adoption lag of rice technology (Mottaleb et al., 2015). Availability of government-approved seed dealers, irrigation facilities, land characteristics, loan facilities; infrastructure, and communications such as roads significantly influence the adoption of modern rice varieties.

The national research institutes (Bangladesh Rice Research Institute-BRRI, Bangladesh Agricultural Research InstituteBARI, Bangladesh Institute of Nuclear Agriculture-BINA, Bangladesh Sugar-crop Research Institute-BSRI, etc.) developed technologies regarding variety, farm machinery, cultivation technique, crop and soil management practices; insect and disease management, etc. They are trying to transfer the technologies to the end-users through public-private partnership (PPP) in collaboration with extension agencies (Department of Agricultural Extension-DAE), other government and non-government organizations. Information and communication technology (ICT) based tools like the websites of the National Agricultural Research and Extension Systems (NARES); social media, electronics, and print media can also be playing a vibrant role in the rapid dissemination of the technology(s) and to 
curtail adoption lag. Now it is high time to find out the way forward to minimize the adoption lag of technologies for doubling rice productivity by 2030 to achieve sustainable development goals (SDG). Rice is cultivating around 11.42 million hectares ( $\mathrm{M} \mathrm{ha}$ ) including 3 seasons (Aus, Aman, and Boro) in Bangladesh (BBS 2018; Karmakar and Ali, 2019) and producing 34.7 million metric ton of cleaned rice which is enough to fulfill the demand of the country (BBS, 2018). However, the self-sufficiency of food is very much vulnerable due to increasing population, declining resources (cultivable land, labor, water, etc.), increasing abiotic (Salinity, drought, cold, etc.) and biotic stress (insect and diseases incidence); natural calamities (flood, flash flood, storm, etc.); and the adverse effect of climate change (Karmakar and Ali, 2019). Around 2.0 million population are adding every year in Bangladesh which required 0.27 million metric tons of cleaned rice annually to feed the growing population (BBS, 2018, Yunus et al., 2019, Karmakar and Ali, 2019). On the other hand, about $0.4 \%$ of agricultural land is converting to non-agricultural land every year to meet up the different needs of the growing population (Hasan et al., 2013; Karmakar and Ali, 2019). Moreover, the area under rice cultivation will have to be reduced to accommodate crop diversification as food habit of the people is changing along with increased income. The demand for other food grains has been increasing rapidly from urbanization and upright growth of per capita income of the country. Therefore, it is a great challenge for Bangladesh to feed the huge population from limited land. The use of modern technologies like high-yielding rice varieties along with farm machinery would be the important avenues to reducing hunger and food insecurity in developing countries (Ghimire et al., 2015).

Promoting the adoption of rice technologies in a sustainable way is very important to improve the productivity as well livelihood of the farmers (Asfaw et al., 2012). The net gain from the adoption of new technology is the key determinant of the adoption, inclusive of all costs of using the new technology (Foster and Rosenzweig, 2010). Availability of quality seed of newly released promising variety(s), competent variety, market price; irrigation facility in time, land tenant system are the key dynamics affecting the adoption of modern rice varieties in Bangladesh (Alauddin and Tisdell, 1996; Hossain et al., 2003). Ghimire et al. (2015) also stated that the availability of quality rice seeds at the field level had a significant influence on the adoption of newly released promising rice varieties as the farmer would have easy access to the local stores to purchase and cultivate new improved varieties. Therefore, the study was aimed to formulate a guideline to minimize the adoption lag of rice variety and to develop action plan for reducing adoption lag to doubling rice productivity and increase food security.

\section{MATERIALS AND METHODS}

\section{Study approach}

The study was accomplished accordingly by reviewing previous works and studies completed on technology adoption. Calculation and estimation of future seed demand and supply accomplished through the temporal pathway. The data used in this study were obtained from scientists, extension personnel, and farmers.

\section{Quantification of rice seed}

During variety release process, at least $128 \mathrm{~kg}$ breeder or quality seeds per variety need to be produced by the concerned research institute for executing action plan. After execution of action plan and varietal diffusion model, adoption lag will be minimized by 5 to 7 years of variety release. Moreover, the seed production and dissemination status of the 
Adaptive Research Division was presented through reviewing the annual report 2000-2001 to 2019-2020 of BRRI.

\section{Concept of adoption lag}

Adoption means bring it up on one's own or choosing to take it up. Adoption lag denotes to fall behind or follow after a delay to receive technology. Adoption lag is defined by the time difference between releasing technology and its reaches to the adoption peak that expressed as a year (Kabir et al., 2015). The time lag between the release and farm-level adoption of the new varieties needs to be reduced (Singh, 2013).

\section{Conceptual framework for minimizing adoption lag}

Adoption system enhancement is very much important to minimize adoption lag. Two major components are the keys to adoption lag minimization. A diagram with major components for adoption lag minimization is given below (Fig. 1).

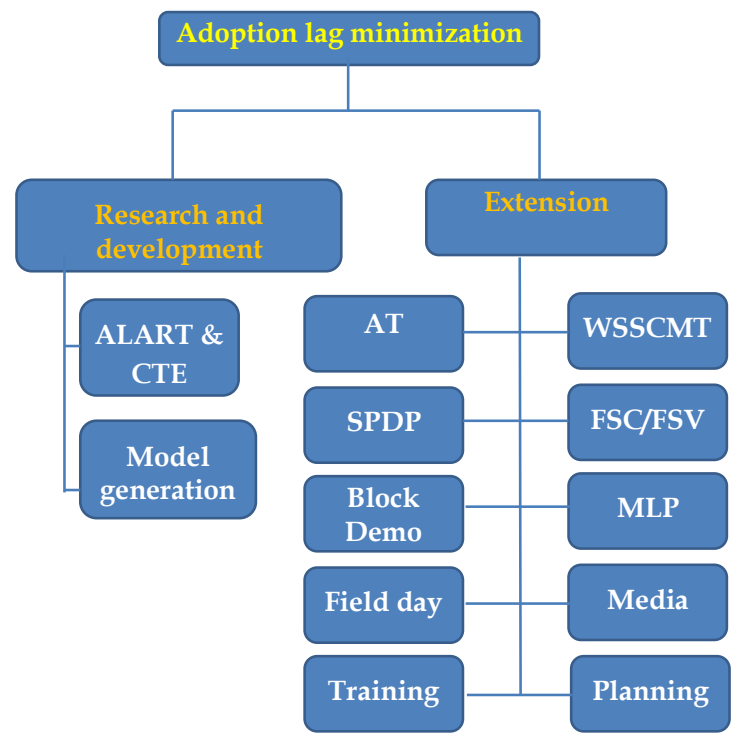

Fig. 1. Conceptual framework for adoption lag minimization.

ALART: Advanced line adaptive research trial; CTE: Component technology evaluation; AT:
Adaptive trial; SPDP: Seed production and dissemination program; WSSCMT: Workshop, Seminar, Symposium, Conference, Motivational tour; FSC: Farmer seed center; FSV: Farmer seed village; MLP: Market linkage and price.

\section{RESULTS AND DISCUSSION}

\section{Empirical experience of varietal dissemination}

Seed Production and Dissemination Program (SPDP) is a fruitful program launching by the Adaptive Research Division (ARD) of BRRI for rapid dissemination of modern rice variety that could be an example for other institutes. Figure 2 shows that after releasing a technology, it required $16 \pm 3$ years to reach its peak from its release (Kabir et al., 2015; Karmakar et al., 2018). The yield gap is another major constraint to achieving the potential yield and doubling the rice productivity. Figure 3 indicated that the gap between potential farm yield and actual is around 20.7\% (Kabir et al., 2015). Therefore, yield gap reduction by $10 \%$ would be a milestone to doubling rice productivity.

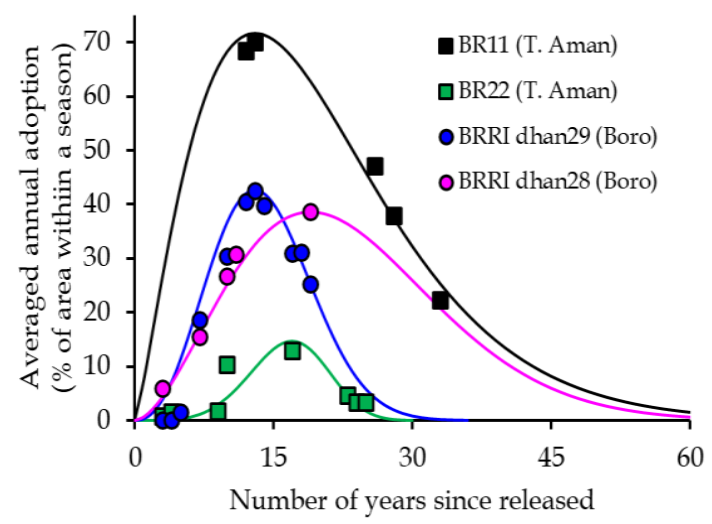

Fig. 2. Adoption curve of four BRRI released rice varieties in three seasons. The curves were well fitted using three parameters Weibull equation using data from Kabir et al., 2015. 


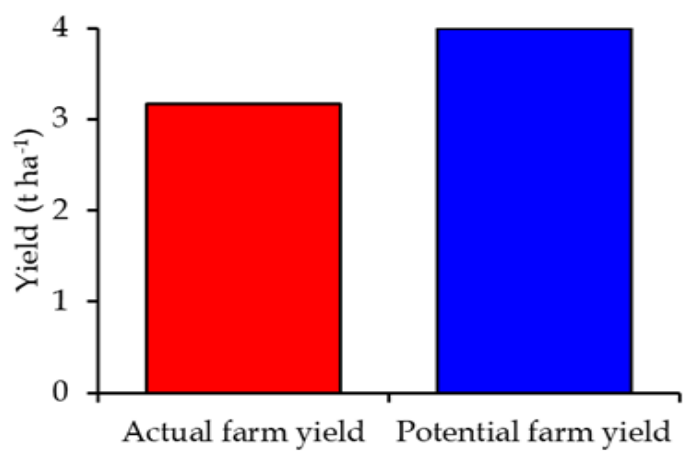

Fig. 3. The actual farm yield and potential farm yield of clean rice in Bangladesh, showing the yield gap of $0.83 \mathrm{t} \mathrm{h}^{-1}$ or $20.7 \%$ (Adopted from Kabir et al., 2015).

For example, ARD of BRRI has the mandate to validate technology(s) developed by different research divisions of BRRI and to transfer the technology. ARD is executing the mentioned activities like technology validation and technology dissemination effectively. Department of Agricultural Extension (DAE) is mainly responsible for technology diffusion; however, the existing national system for technology transfer is lengthy and time-consuming. Therefore, ARD has set up a small scale of adaptive trials and frontline demonstrations of newly released rice varieties to enhance the dissemination process. We reviewed the dissemination activities of ARD from 20002001 to 2019-2020 conducted throughout the country. Most of the rice varieties developed by BRRI were demonstrated at farmers' fields during the period. A total of 4254 metric ton grain was produced of which 804 tons $(18 \%)$ were preserved as seed for the use of succeeding season that was contributed significantly to the diffusion of the varieties (Fig. 4) and the farmers' motivation was $20 \%$ (Fig. 5). We need to minimize adoption lag by reducing the yield gap by utilizing all sorts of tools to bridging up the adoption lag and increase rice yield and productivity.

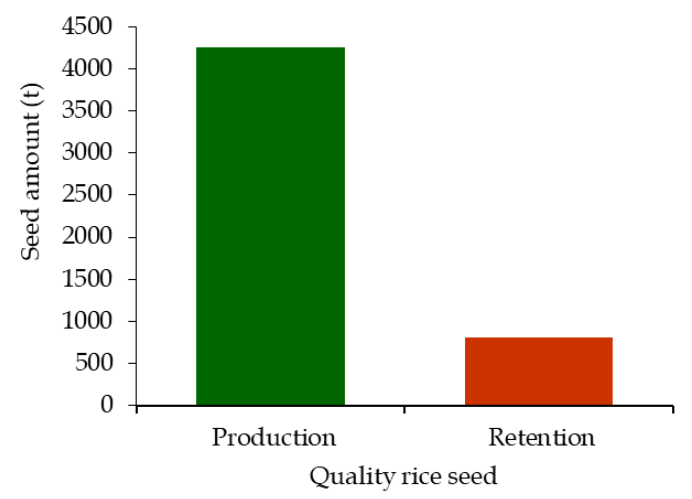

Fig. 4. Quality seed production and retention (18\%) by farmers during 2000-2001 to 2019-2020 through demonstration conducted by the ARD of BRRI, Gazipur.

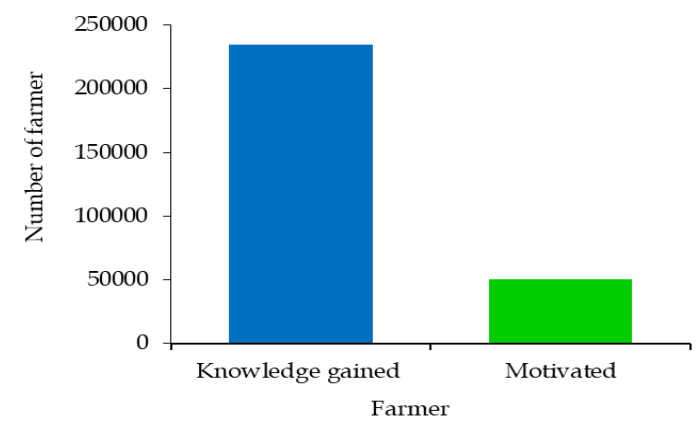

Fig. 5. Knowledge gained and motivated farmers $(20 \%)$ during 2000-2001 to 2019-2020 through demonstration conducted by the ARD of BRRI, Gazipur.

\section{Action plan for varietal adoption lag minimization}

An action plan is very much important for the proper implementation of a program and to reach the target. Therefore, we formulated an action plan for rice technology adoption through to 2050 (Table 1). Several coordinated programs need to be executed for the adoption lag minimization. The prime factor for adoption lag is the dispersion rate of the technology during the diffusion stage of first three years' adoption rate after the release of the technology. If this diffusion stage can suggest quick acceptance of technology, then its adoption rate should be high and adequate preparation might decrease adoption lag. 
Table 1. Action plan for adoption lag minimization

\section{Theme Programme Action}

\begin{tabular}{|c|c|c|}
\hline \multirow{2}{*}{ 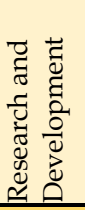 } & $\begin{array}{l}\text { ALART } \\
\text { and CTE }\end{array}$ & $\begin{array}{l}\text { - Authentic, independent and multi-stakeholder evaluation (Modification and acceptance of } \\
\text { product profile) } \\
\text { - Validation and recommendation of advanced breeding line }\end{array}$ \\
\hline & $\begin{array}{l}\text { Model } \\
\text { generation }\end{array}$ & $\begin{array}{l}\text { - Identification of field applicable technology dissemination (FATD) model } \\
\text { - } \quad \text { Calibration and validation of FATD model }\end{array}$ \\
\hline \multirow{10}{*}{ 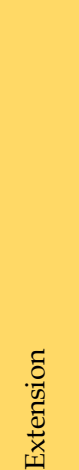 } & AT & Validation and selection of location-specific suitable variety and component technology \\
\hline & SPDP & $\begin{array}{l}\text { - Location-specific demand-based seed production } \\
\text { - Need-based seed distribution }\end{array}$ \\
\hline & Block Demo & - Awareness building and bulk seed production \\
\hline & Field day & Create awareness to mass population \\
\hline & Training & $\begin{array}{l}\text { - Trained up of extension personnel and lead farmers } \\
\text { - Trained up of community influencers (Agriculture trader, Local leader, Teachers, Imam, etc.) }\end{array}$ \\
\hline & WSSCMT & Motivation through interaction and knowledge sharing \\
\hline & FSC/FSV & Easy access to quality seed at farm level \\
\hline & MLP & Ensure fair price \\
\hline & Media & - Rapid dissemination of information flow \\
\hline & Planning & - Feedback from stakeholders and variety diffusion rate report \\
\hline
\end{tabular}

ALART: Advanced line adaptive research trial; CTE: Component technology evaluation; AT: Adaptive trial; SPDP: Seed production and dissemination program; WSSCMT: Workshop, Seminar, Symposium, Conference, Motivational tour; FSC: Farmer seed center; FSV: Farmer seed village; MLP: Market linkage and price

\section{Technology validation and evaluation}

BRRI tests the adaptability and suitability of the advanced breeding lines or technology through conducting a trial named advanced line adaptive research trial (ALART) or component technology evaluation (CTE) at only a few (8 to 12) locations throughout the country in different agro-ecological conditions. But it is needed to conduct the trials at more locations covering all the agro-ecological zones of the country to investigate location-specific adaptability and suitability to generate more information about the technology, especially for a new genotype.

Evaluation of new genotype or technology is very much important. Authentic ALART/CTE can trigger adoption rate largely and subsequently reduce adoption lag. Therefore, proper evaluation based on authentic data collected by following appropriate methodology will be ensured during this process. Standard check variety/technology is to be selected rationally covering specific objectives. After evaluation, a recommendation will be based on authentic results with appropriate statistical analysis. The product profile of the advanced line(s)/technology will be supplied before the setup of the trial with judicial check(s) selection. For example, if the objective of the new advanced line is to replace BRRI dhan28, then the product profile should be better than BRRI dhan28 in all respect and should also supersede the last improvement of the similar genotype like BRRI dhan88 and/or BRRI dhan96.

All the concerned beneficiaries will be involved in the evaluation of new technology to find its suitability in the existing circumstances (Mwangi and Kariuki, 2015). Therefore, all the stakeholders like farmers, extension agencies, NGOs, companies, seed producers, dealers, millers, traders, etc. will be invited during the evaluation of technology. They will evaluate the technology for choosing the better one and subsequently, the 
technology(s) will be more sustainable. In addition, awareness will be built up during the evaluation of the technology which might trigger adoption after release. Moreover, multi-stakeholders' independent evaluation will make the process more authentic, transparent, reliable, and sustainable.

\section{Model for technology adoption}

In a technology dissemination process, farmers (ultimate users), producers (seed or equipment), extension personnel, and researcher are very closely related and interconnected for technology adoption (Fig. 6). If one of the stakeholders becomes inactive then, adoption will be interrupted. For example, in an AT or SPDP, if new improved varieties are demonstrated along with the local popular check variety in the same piece of land with the appropriate production technology of the respective varieties, then the varieties will show their yield potentiality. Extension personnel will select a local seed producer or a farmer's group like integrated pest management (IPM) club integrated crop management (ICM) club, common interest group (CIG), etc. who will collect the seed produced in AT or SPDP. The researcher will select the production package of the varieties to be followed. Seed producers and extension personnel will select suitable land and farmer for the trial. Local seed producers will collect seeds of farmers' selected variety(s) and will sell them in the next year. This model is formulated by Rahman et al. (2020). Seed selling rate will indicate the dissemination rate of the variety.

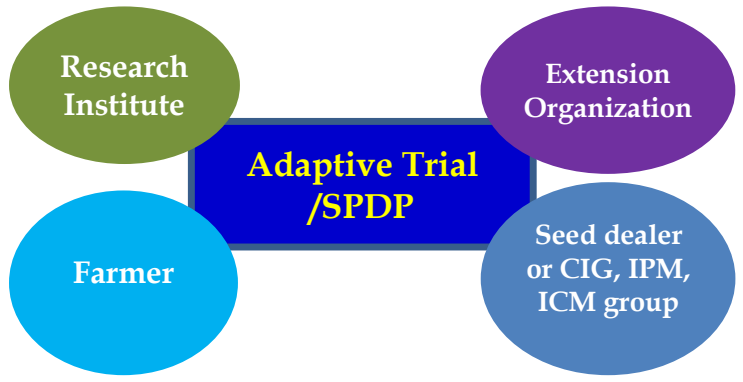

Fig. 6. Mode l: demonstration with 4-Stakeholders.

\section{Model for varietal diffusion}

In the first year of variety release, a number of AT or SPDP will be set up based on the availability of seed. For example, if $128 \mathrm{~kg}$ seed/variety is available, then 64 trials will be set up in 64 districts. In $2^{\text {nd }}$ and $3^{\text {rd }}$ years, 128 AT/SPDP will be conducted in 64 districts @ 2AT/SPDP per district. Then $256 \mathrm{~kg}$ seed/variety will have to be supplied by the research institute.

The extension organization will supervise the trials along with BRRI. In every trial, a field day will be organized to know the feedback of farmers and other stakeholders. The seed of farmers' chosen variety(s) will be collected, stored, and marketed by the local seed producer or IPM/ICM/CIG farmers group and they will provide this information to the extension organization and BRRI. At least 10 to $20 \%$ seed selling information will be checked by the concerned scientist of BRRI every year and total seed selling data will be calibrated based on the checked data. Similarly, the next two years' trial data will be collected from conducted trials and associated seed producer/dealer/farmers' club/groups. After three years, compiling all the data, the researcher will be able to show the rate of dissemination of a variety during the diffusion stage (Fig. 7). Based on the reports of diffusion stage, the research institute will be able to give a projection of adoption lag of the new variety(s) indicating the role of other national components like Bangladesh Agricultural Development Corporation (BADC), Seed Certification Agency (SCA) and Department of Agricultural Extension (DAE), etc.

\section{Adaptive trial for varietal adoption}

Sufficient quantitative information/data are required for varietal replacement decisions from a greater number of trials across the country. Therefore, an adequate number of adaptive trial (AT) or head-to-head adaptive trials (HHAT) need to be conducted throughout the country for generating sufficient 
information leading to massive scaling up the decision of newly released varieties in the target environments. Moreover, the seed dissemination system in Bangladesh is also slow and lingering. Therefore, AT will also play a significant role to replace old mega varieties with the latest ones and it also has a vital contribution for rapid dissemination. Farmers' rally and field day will be conducted on the performances of modern rice varieties. Suitable and better performing variety(s) will be selected by the farmers from those HHAT of specific environment for large scale diffusion. Farmers also are suggested to preserve quality seeds of the selected variety(s) for next year's use. On the other hand, seed-producing agencies will multiply seeds of the promising ones.

\section{Awareness build-up during advanced genotypes evaluation}

Research organizations test the adaptability of the advanced breeding lines through conducting trial named advanced line adaptive research trial (ALART) at only 8 to 10 locations throughout the country due to resource constraints. But it is essential to conduct the trials at more locations covering all the agro-ecological zones of the country to investigate location specific adaptability and to generate more information about the advanced genotypes. Awareness need to be buildup during evaluation of the genotypes evaluated under ALART. It is therefore important that the end users should be involved in the evaluation of new technology to be introduced to farmers and they find its suitability to their circumstances (Mwangi and Kariuki, 2015). All the stakeholders like farmer, extension agencies, NGO, company, seed producers, dealer, miller, trader etc. will be invited at maturity stage of the crop for evaluation. They evaluate the genotypes and chose the better ones for specific environment, and then the technology(s) will be more sustainable.

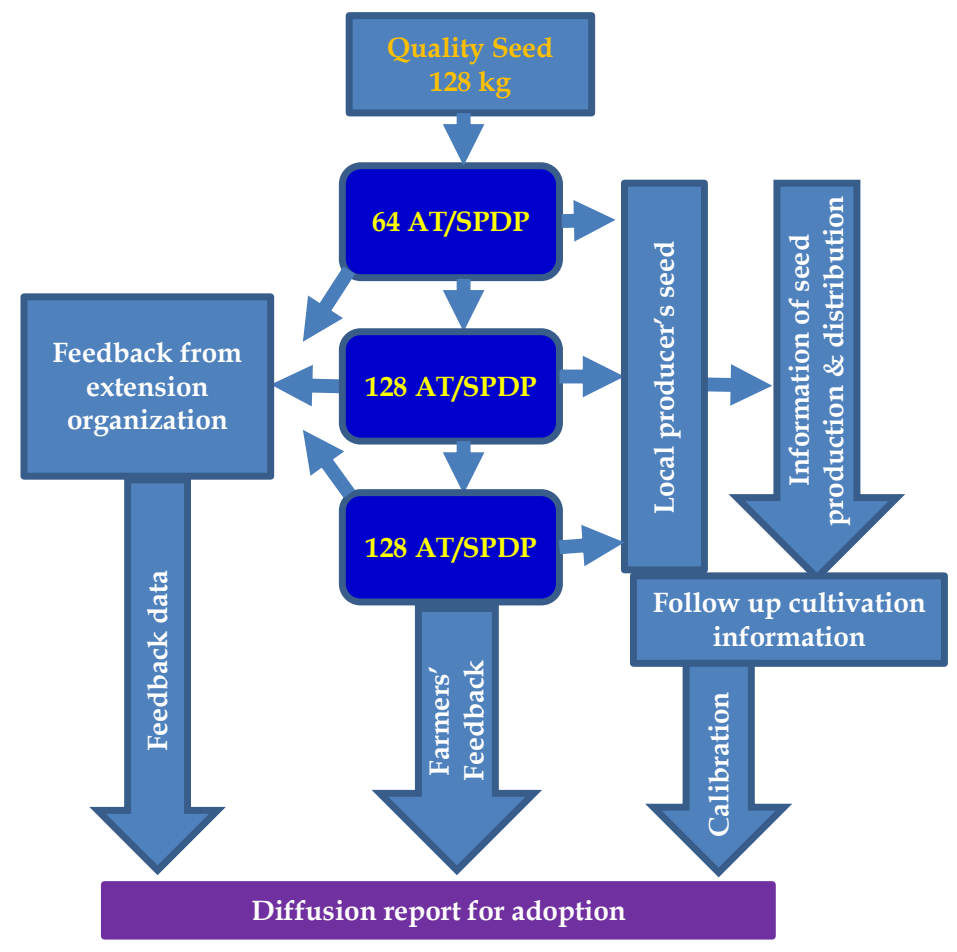

Fig. 7. Model of varietal diffusion to guide future adoption plan. 


\section{Component Technology Adoption}

A good variety without appropriate management, yield tends to zero. Consequently, management practices are very much important to get higher yield and to achieve higher productivity of a variety. The research institutes developing diversified varieties based on different agroecological zones (AEZ), environments (salinity, drought, flood, submergence, water stagnant, cold etc.), product profile, cropping pattern and so on. Growth duration of the varieties varied highly ranged from 100 to 170 days (BRRI, 2020). Therefore, variety specific management (VSM), location specific management (LSM), Integrated pest management (IPM), Integrated Crop management (ICM), Line Logo Perching (LLP) etc. are now time-demand to obtain optimum yield and productivity. For example, BRRI dhan75 is low input responsive short duration (105-110 days) green super rice. Optimum seedling age for transplanting of this variety would be 15 to 20 days. Sometimes, farmers transplant older seedlings (30-40 days) of this variety and panicle emerged within few days after transplanting; finally yield reduced drastically. Therefore, we have to follow good agricultural practice (GAP). Crop management practices vary from one AEZ to another AEZ. For example, agronomic (crop and fertilizer) management for saline environment must be different from drought environment. Therefore, variety and location specific managements need to be followed to achieve higher yield and productivity.

\section{Seed production and dissemination program (SPDP)}

Demonstrations with 2-stakeholders (extension agencies-farmers) and 3-stakeholders (research organization-extension agencies-farmers) are being practiced in Bangladesh (Fig. 8). However, the effectiveness and sustainability of technology transferred through these models are not at par level. Therefore, including more stakeholders for the demonstration and adoption of technology will be more effective and sustainable.

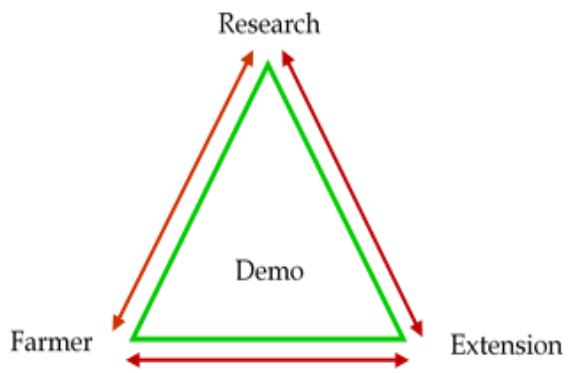

Fig. 8. Model demonstration with 3-Stakeholders.

Demonstrations of the selected varieties/technology(s) in collaboration with 4stakeholders (research organization-extension agencies-farmers-seed dealers/traders), 5stakeholders (research organization-extension agencies-farmers-seed dealers/traders-formal seed agencies) and 6-stakeholders (research organization-extension agencies-farmers-seed dealers/traders-formal seed producing agenciesseed certification agency) (Fig. 9) will be more effective instead of the existing 2- stakeholders (Extension agencies and farmers), and 3stakeholders (research organization-extension agencies-farmers). Formal seed producers of Bangladesh (GO, NGO, and company) are producing and supplying almost $50 \%$ rice seed, and the rest of the seeds come from informal systems (farmers) (Iqbal and Toufique, 2016; Karmakar and Ali, 2019). Therefore, quality seed production and storage at the farmers' level are equally important. Sometimes dealers are the key factor to select variety/technology/ management options to be used by the farmers. Consequently, the involvement of seed dealers in the demonstration will speed up adoption. We encourage farmers to produce quality rice seeds through SPDP. Accordingly, they can produce and use their seed next season. But farmers could not sell the seeds that remained after their use. In this channel, seed dealers can buy quality seeds from the farmers and those will be sold to farmers next year. Then farmers will be benefitted financially through selling quality seeds. 


\section{Block demonstration}

Demonstration of a new variety conducted generally 1 to 3 bigha (33-99 decimal). But it is not able to create a significant impact on the farmers, millers, businessmen, and consumers. Therefore, bigger size demonstrations like 1.34 to 13.4 hectares (10 to 100 bigha) have to set up in a place that will have a remarkable impact to change the attitudes of the stakeholders and to minimize adoption lag.

\section{Field day}

It is very important to demonstrate the results and field performance of promising rice varieties to the stakeholders. Then farmers and other stakeholders could easily be understood and build up confidence about the technology by "Seeing is believing" through Field day. Field day creates awareness and interest about the varieties and other technologies among farmers, local leaders, elite persons, extension personnel, seed dealers/traders. Consequently, large numbers ( $20 \%$ of total demonstration) of a field day on the performance of the varieties need to be conducted. Interested farmers and traders will be identified from field days to produce seeds of selected varieties.

\section{Training}

Large numbers of training on modern rice variety, crop management practices, seed to seed technology (seed production, processing, storage, and packaging); and other technologies are very much important for farmers and extension personnel to update their knowledge and skill. A rice production manual having all the practical aspects of seed-to-seed technology will be provided in the training programs.

The training will be operated in collaboration with BRRI and extension agencies for the sustainable adoption of technology. Generally, most of the farmers' training is conducting at upazila level. The main drawback in existing training is that the same farmers/participants receiving the same training several times while a vast number of farmers are left behind without getting updated training on rice technology. An intervention with innovation is now the time-demand to overcome this problem. The farmers' training on agricultural technology will be organized and conducted at the root level (village level) instead of upazilabased training. This effort will increase knowledge, skill, and updated information about the technology. It will also help to enhance technology diffusion and adoption to the endusers reducing adoption lag.

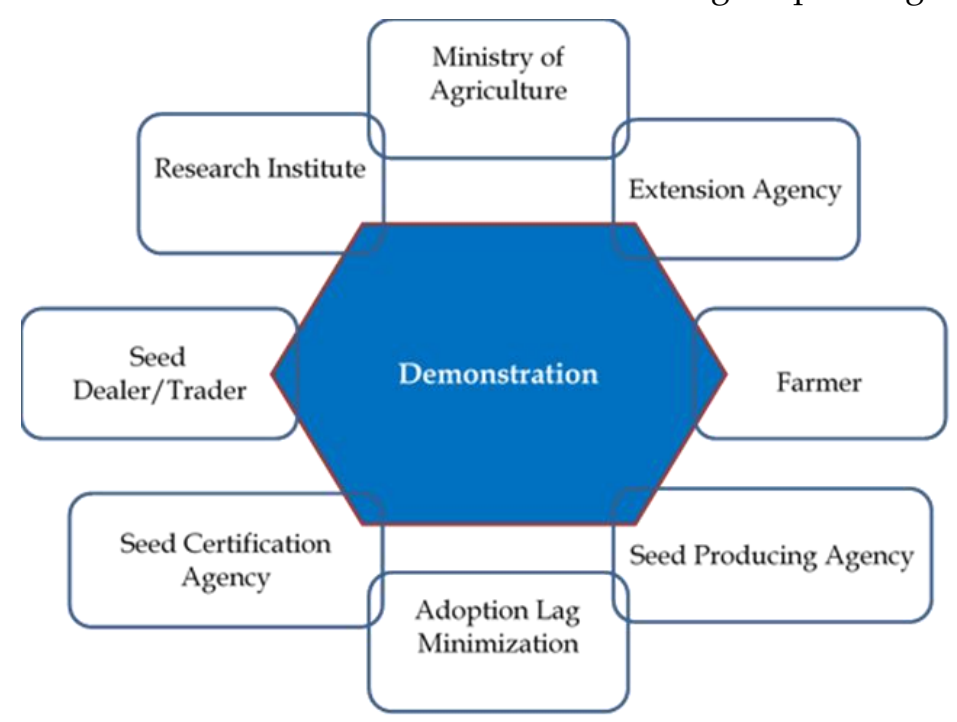

Fig. 9. Model demonstration with 6-stakeholders.

84 Karmakar et al. 


\section{Workshop/Seminar/Symposium/Conference}

Workshop/Seminar/Symposium/Conference among all the stakeholders will have a significant effect to increase adoption of newly released variety(s) as well technology. Workshop on rice technology will be arranged on an agricultural region basis and also centrally. Location/region specific many problems and prospects will be come-out in the workshops. All the stakeholders will be benefitted mutually through the workshop and adoption lag will be minimized through steps taken based on the recommendations.

\section{Motivational tour}

Technology adoption and dissemination significantly vary from region to region, location to location; even in a small distance. Motivational tours of the farmers to observe the successful adoption of technologies have a significant impact on adoption. Farmers of a region brought out another region/location could observe physically the technology and its technical know-how. They discuss with the adopted farmers and can learn the success story. Adoption level could be enhanced in this process when farmers heard and observed about the technology from other farmers and then, their confidence level must be improved to accept and practice the technique.

\section{Farmers seed center/village establishment}

Nowadays farmers are very much reluctant to grow and preserve seed at the farm level. They are habituated to buy packet seed from the market/dealers. The establishment of Farmers Seed Center (FSC) /Seed village/Technology village is another effective option to make availability of quality seeds of newly released promising rice variety and other technologies at farm level for rapid dissemination (Kabir et al., 2019). FSC builds up storage facilities of seeds and also increases the availability of quality seeds at the field level. It will change farmer's attitudes and perceptions regarding seed storage and the use of the self-stored seed. It will also encourage other farmers for storing and using of own quality seed.

\section{Market linkage and price}

Market linkage and price of rice are the imperative determinants for adopting a variety and technologies. Block demonstration linking with all the stakeholders like farmers, extension agencies, researchers, seed producers, seed dealers, rice millers, and businessmen will create a marketing channel of rice. Government is very much enthusiastic to increase rice prices and decrease production costs. Rice price needs to be increased at par level and it should be higher than the production cost. Then farmers will be encouraged to produce more rice with proper care that would have positive effects to increase adoption.

\section{Publications and media coverage}

Print and electronic media can play a vital role to build up awareness about the technology. Media coverage of promising technologies need to be increased to enhance technology adoption. Then suitable technologies will rapidly be disseminated to the farmers and stakeholders. Leaflets, booklet, journal, book, etc. on smart technologies will be published by BRRI which will increase technology adoption directly and indirectly. Social network effects are important for individual decisions. Farmers can share information and learn from each other in the particular context of agricultural innovations (Uaiene et al., 2009). Usage of web portals and websites of the concerned organizations; and social media will have a significant role to cognizant about the technologies to mass populations that enhance adoption through disseminating rice technologies rapidly.

\section{Planning for rapid adoption}

The diffusion stage is very important for the adoption of a variety or technology. In the first three years of a variety release, a number of demonstrations will be conducted throughout the country following the model demonstration with four stakeholders shown in Figure 6. Then 
the feedback of the stakeholders, seed production and selling information of local seed producer or farmers' group (IPM/ICM/CIG), follow up cultivation information will provide much information about dissemination and spreading of the variety (shown in Figure 7). After three years, compiling and analyzing all the information, the researcher will prepare a report of the diffusion stage mentioning the rate of dissemination of the variety. In the report, BRRI will give a projection of the adoption lag of the new variety(s) indicating the specific role of other national organizations like BADC, SCA, DAE, etc. Collaborative and collective efforts of national organizations based on the recommendation and suggestion of the report will reduce adoption lag largely.

An effective seed system denotes the activities of quality seed multiplication, storing and distribution, and the use of these quality seeds by farmers for growing crops. It has close linkages with other systems, particularly research and extension (Singh and Singh, 2016). The role of the actors in the seed systems is very imperative to reduce adoption lag by enhancing seed availability to the farmer. The present seed system in Bangladesh is slow and lingering. The formal seed producers/agencies produce seeds of popular varieties as a business model. The new variety takes many years for getting its popularity in the existing seed system. It is now high time to make an intervention in this system for rapid dissemination of newly released promising variety.

For rapid popularization, extension agencies will estimate upazila-wise demand of seed for the newly released potential rice cultivars through conducting adaptive trials of the newly released varieties in collaboration with research organizations in the $1^{\text {st }}$ year of variety release. After getting a positive response of varietal acceptance by the farmers, the extension agencies will inform the requirement to the seedproducing agencies at well-ahead of commencing seed production program for the following seasons with an assurance for the marketing of the seed (Kabir et al., 2019). A model of an improved seed system is presented in Figure 10 for rapid dissemination and adoption lag minimization of newly released rice variety(s).

\section{Implementation strategy}

The activities will be executed through a public-private partnership (PPP) having strong collaborations and linkages among the stakeholders (Ministry of Agriculture, research institutes, extension agencies, seed producing agencies, seed certification agency, farmers, seed dealers/traders and millers).

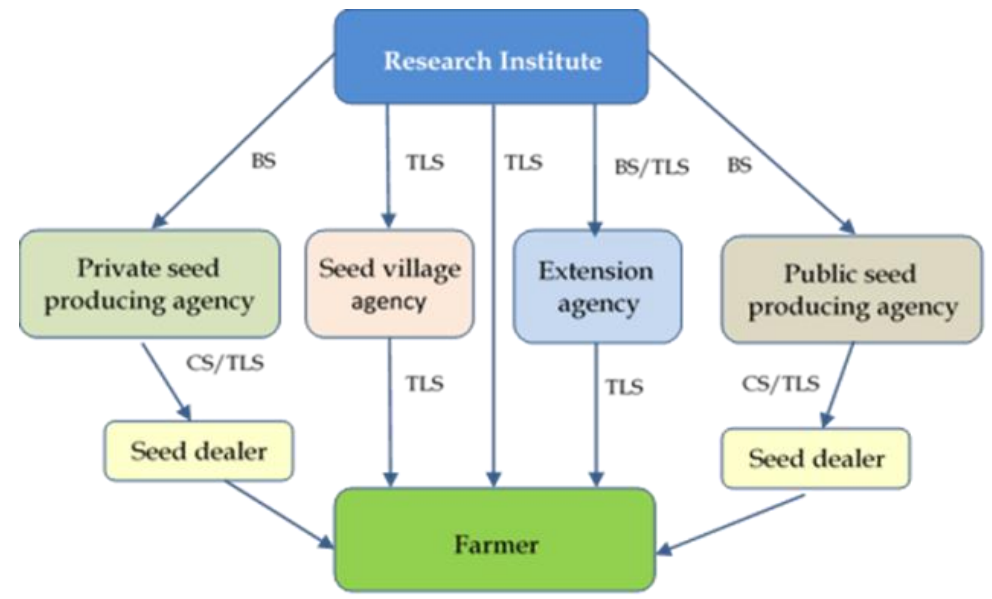

Fig. 10. Seed system model for rapid dissemination and adoption lag minimization. Note: BS=Breeder seed, CS=Certified seed and TLS=Truthfully labeled seed 


\section{CONCLUSION}

Technology dissemination with integrated approaches like an authentic and multistakeholder evaluation of advanced genotypes or component technology, adequate field applicable demonstration of the technology, proper adoption plan based on diffusion information, and speedy availability of seeds to farmers would boost up technology adoption for minimizing adoption lag. Adoption of newly released rice variety would be possible within five to seven years if the formulated action plan and adoption lag minimization models could be practiced. Combined efforts of farmers, researchers, extension personnel, and the Government of Bangladesh would be enabled to minimize adoption lag by 2030 that could be a vital role in doubling the rice productivity and sustainable food security.

\section{RECOMMENDATION}

> Production of breeder, foundation, certified and quality seeds; and their supply need to be ensured by the concerned organizations in time.

$>$ Action plan need to be primed to execute the strategies and model for adoption lag minimization and rapid dissemination of promising technology(s).

$>$ Varietal replacement rate (VRR), seed multiplication rate (SMR) and seed replacement rate (SRR) of new varieties have to be increased at par level.

$>$ Strengthening linkage among research institutes, extension agencies, farmers and public-private partnership (PPP).

$>$ Manpower of research institutes especially for BRRI should be increased.

$>$ Training and workshop on modern rice technology need to be organized and executed in collaboration with all the stakeholders.

\section{ACKNOWLEDGEMENTS}

The authors highly acknowledge the contribution and support of BRRI authority; Scientists of the Adaptive Research Division, Regional Stations, and other concerned Divisions. We thank Dr AKM Saiful Islam, PSO, FMPHT Division, BRRI, Gazipur for valuable suggestions and comments.

\section{REFERENCES}

Abdulai, S, A Zakariah and S A Donkoh. 2018. Adoption of rice cultivation technologies and its effect on technical efficiency in Sagnarigu District of Ghana. Cogent Food $\mathcal{E}$ Agriculture, 4: 1-14. https:// doi.org/10.1080/23311932.2018.1424296

Adesina, A A and M M Zinnah. 1993. Technology characteristics, farmers' perceptions and adoption decisions: A Tobit model application in Sierra Leone. Agricultural Economics, 9: 297-311.

Alauddin, M and C Tisdell. 1996. Market analysis, technical change and income distribution in semisubsistence agriculture: the case of Bangladesh. Agricultural Economics, 1 (1): 1-18.

Asfaw, S, B Shiferaw, F Simtowe and L Lipper. 2012. Impact of modern agricultural technologies on smallholder welfare: Evidence from Tanzania and Ethiopia. Food Policy, 37 (3): 283-295.

Ashby, J and L Sperling. 1992. Institutionalizing participatory, client-driven research and technology development in agriculture. Paper presented at the meeting of the CGIAR Social Scientists, 15-22 September 1992, The Hague, The Netherlands, pp. 115-122.

BBS (Bangladesh Bureau of Statistics) 2018. Statistics of major crops. Statistics and Informatics Division (SID), Bangladesh Bureau of Statistics, Government of the People's Republic of Bangladesh. pp 21-22.

BRRI (Bangladesh Rice Research Institute) 2020. Adhunik Dhaner Chash (Modern Rice Cultivation), Gazipur, Bangladesh. pp. 5-101.

Foster, D and M Rosenzweig. 2010. Learning by doing and learning from others: Human capital and technical change in agriculture. Journal of Political Economy, 103 (6): 1176-1209.

Ghimire, R, H Wen-chi and R B Shresta. 2015. Factors affecting adoption of improved rice varieties among rural farm households in central Nepal. Rice Science, 22 (1): 35-43.

Haque, A H M M , F A Elazegui, T M A Mia, M M Kamal and M M Haque. 2012. Increase in rice yield through 
the use of quality seeds in Bangladesh. African J. of Agricultural Research, 7 (26): 3819-3827.

Hasan, M N, M S Hossain, M A Bari and M R Islam. 2013. Agricultural land availability in Bangladesh. Soil Resource Development Institute, Dhaka, Bangladesh, pp. 1-42.

Hossain, M, L David, M L Bose and A Chowdhury. 2003. Rice research technological change, and impacts on the poor: The Bangladesh case (Summary Report). EPTD discussion paper no. 110. Washington, DC: International Food Policy Research Institute.

Iqbal, K and K A Toufique. 2016. Formal vs Informal seeds: Adoption and productivity differences. Bangladesh Development Studies, XXXIX (1 and 2): 59-81.

IRRI (International Rice Research Institute) 2013. Training Manual of Seed quality. Post-harvest Unit. Crop and Environmental Sciences Division, International Rice Research Institute.

Kabir, M J, M A Islam, M C Rahman, M S Rahaman, M S Kabir and M A B Siddique. 2019. Diffusion of Wet Season (T. Aman) Rice Cultivars under Changed Environment in Northwest Bangladesh. Bangladesh Rice J., 23 (1): 81-106.

Kabir, M S, M U Salam, A Chowdhury, N M F Rahman, K M Iftekharuddaula, M S Rahman, M H Rashid, S S Dipti, A Islam, M A Latif, A K M S Islam, M M Hossain, B Nessa, T H Ansari, M A Ali and J K Biswas. 2015. Rice vision for Bangladesh: 2050 and Beyond. Bangladesh Rice J., 19 (2): 1-18.

Kabir, M S, M U Salam, A K M S Islam, M A R Sarkar, M A A Mamun, M C Rahman, B Nessa, M J Kabir, H B Shozib, M B Hossain, A Chowdhury, M Nasim, K M Iftekharuddaula, M S Hossain, M K A Bhuiyan, B Karmakar, M S Rahman, M M Haque, M T Khatun, M P Ali, S M H A Rabbi, P L Biswas, E S M H Rashid and N M F Rahman. 2020: Doubling rice productivity in Bangladesh: A way to achieving SDG 2 and moving forward. Bangladesh Rice Journal, 24 (2): 1-47.

Karmakar, B, K M Iftekharuddaula, B Ahmed, N M F Rahman, M S Kabir, M A Ali, T L Aditya, M R Islam, M U Salam and G Atlin. 2018. Progress of Head to Head Adaptive Trials with new Boro rice varieties in Bangladesh. Poster paper presented in the International Workshop "Transforming Rice Breeding: Breeding Program Modernization Initiative" held at Raipur, Chhattisgarh, India on 8-10 October 2018.
Karmakar, B and M A Ali. 2019. Production and preservation of quality rice seed. Publication no. 282, $1^{\text {st }}$ Edition, Bangladesh Rice Research Institute (BRRI), Gazipur, Bangladesh. pp.1-36.

Loevinsohn, M, J Sumberg and A Diagne. 2012. Under what circumstances and conditions does adoption of technology result in increased agricultural productivity? Protocol. London: EPPI Centre, Social Science Research Unit, Institute of Education, University of London. pp.1-31.

Mottaleb, K, S Mohanty and A Nelson. 2015. Factors influencing hybrid rice adoption: A Bangladesh case. Australian J. of Agricultural and Resource Economics, 59 (2): 258-274.

Mwangi, M and S Kariuk. 2015. Factors Determining Adoption of New Agricultural Technology by Smallholder Farmers in Developing Countries. Journal of Economics and Sustainable Development, 6 (5): 208-216.

Rahman, M M, B Karmakar, M A Hossain, M Ibrahim, B Ahmed and M H Kabir. 2020. Model demonstration for rapid dissemination of agricultural technology. In: "Compendium of the International Conference on Sustainable Agriculture and Rural Development: Road to SDGs" held at Sylhet Agricultural University, Sylhet, Bangladesh organized by Bangladesh Agricultural Extension Society (BAES) on 23-24 January 2020. p100-101.

Singh, G and S R Asokan. 1992. Seed Replacement Rate: Some Methodological Issues, IIMA Working Papers WP199211-01_01141, Indian Institute of Management Ahmedabad, Research and Publication Department.

Singh, R P and S Singh. 2016. Optimising seed replacement rates in Jharkhand: Present scenario, challenges and opportunities. Jharkhand J. of Development and Management Studies, 14 (2): 6987-7007.

Singh, R P. 2013. Issues and strategies to correct missing links in seed sector of India. Journal of Research, 25 (1): 1-15.

Uaiene, R, C Arndt and W Masters. 2009. Determinants of Agricultural Technology Adoption in Mozambique. Discussion papers No. 67E.

Yunus, M, S Rashid and S Chowdhury. 2019. Per capita rice consumption in Bangladesh. International Food Policy Research Institute (IFPRI), Bangladesh, pp.1-14. 